\title{
Female sterilisation in rural Bihar: what are the acceptor characteristics?
}

\author{
Amardeep Thind
}

\begin{abstract}
Objective The National Population Policy aims to expand voluntary and informed use of contraceptive services. This paper examines the determinants of use of female sterilisation versus other contraceptive methods in rural Bihar, one of the most socially and economically deprived states in India.
\end{abstract}

Methods Data for 1378 ever-married women aged 15-49 years in rural Bihar, who are currently using contraception, were abstracted from the Second National Family Health Survey. A logistic regression model was developed to understand the determinants of use of female sterilisation versus other contraceptive methods.

Results Maternal age, the number of living sons, religion, scheduled caste/tribe/backward class status, exposure to mass media and household standard of living are statistically significant determinants of the choice between sterilisation and other contraceptive methods.

Conclusion The study underscores the need to significantly broaden the contraceptive choice for women in rural Bihar.

J Fam Plann Reprod Health Care 2005; 31(1): 34-36 (Accepted 4 November 2004)

\section{Key message point}

- Data from the Second National Family Health Survey (NFHS-2) reveal that maternal age, number of living sons, religion, scheduled caste/tribe status, media exposure to family planning and standard of living play a role in determining the choice between sterilisation and other contraceptive methods.

\section{Introduction}

India's National Population Policy (NPP), adopted in 2000 declares population stabilisation a key strategic objective to be attained, among other ways, by providing universal access to information/counselling, fertility regulation and contraceptive services. ${ }^{1}$ The NPP places great store on the expansion of voluntary and informed use of contraceptive services. Of the estimated 168 million eligible couples in the country, only $44 \%$ are thought to be using effective contraception. ${ }^{1}$ Female sterilisation remains by far and above the most common contraceptive method in the country. Data from the Second National Family Health Survey (NFHS-2) show that sterilisation accounts for $75 \%$ of total contraceptive use; nearly $34 \%$ of currently married women are sterilised. ${ }^{2}$

Department of Health Services, UCLA School of Public Health, Los Angeles, CA, USA

Amardeep Thind, MD, PhD, Assistant Professor

Correspondence to: Dr Amardeep Thind, Department of Health Services, UCLA School of Public Health, Room 31-299 CHS, Box 951772, Los Angeles, CA 90095-1772, USA. Tel: +1 310794 4991. Fax: +1 310206 4722. E-mail: amardeep@ucla.edu
In order to attain the goals of the NPP, it is of prime importance to understand the determinants of contraceptive choice in the country. This paper attempts to understand the determinants of use of female sterilisation versus other contraceptive methods in rural Bihar, one of the most socially and economically deprived states in India.

\section{Methods}

Research question

Among ever-married women aged 15-49 years in rural Bihar who are currently using contraception, what are the determinants of use of female sterilisation versus other contraceptive methods?

\section{Data source}

Data for rural Bihar were abstracted from NFHS-2. The study population was ever-married women aged 15-49 years who are currently using contraception $(n=1378)$.

Model and variable specification

Dependent variable. A binary dependent variable was created. Ever-married women aged 15-49 years who reported female sterilisation as their current contraceptive method were labelled as users of 'sterilisation'; women who reported the use of condoms, intrauterine devices (IUDs), pills, male sterilisation or the withdrawal method were labelled as users of 'other methods'. Women not currently using any contraceptive method $(n=4959)$ were excluded from the analyses.

Independent variables. Determinants of contraceptive use were grouped into two categories: variables at the individual and household levels. Individual-level predictors were: maternal age, number of living sons, number of living daughters, maternal education, paternal education, religion, scheduled caste/scheduled tribe status (see Author Note) and media exposure to family planning through radio, TV or poster. Household-level influences were measured by household size, household standard of living (as defined by the NFHS-2), health care-seeking decision maker, and whether the woman required permission to visit friends or go to the marketplace.

\section{Data analysis}

Data analysis was carried out using Stata/SE Version $8^{\mathrm{TM}}$ (StataCorp LP, College Station, TX, USA). The unit of analysis was a woman aged 15-49 years who is currently using a contraceptive method. Bivariate associations were checked using the Chi-square $\left(\chi^{2}\right)$ test. Logistic regression models were utilised to estimate the parameters specified in the behavioural model. Standard errors were adjusted for clustering at the village level $(n=170)$. The overall fit of the model to the data was assessed with the maximum log likelihood ratio $\chi^{2}$ statistic. Multicollinearity and interaction effects were evaluated for the model.

\section{Results}

Descriptive analyses

Of the 1378 women who reported that they were currently using contraception, nearly $80 \%(n=1105)$ mentioned female sterilisation as the method. The remaining $20 \%(n=$ 273 ) were using condoms, pills, IUDs, male sterilisation or the withdrawal method. On bivariate analyses, significant 
associations between female sterilisation and the following variables were noted: maternal age, number of living sons, maternal and paternal education, religion, scheduled caste/scheduled tribe status, media exposure to family planning, household standard of living and the health careseeking decision maker (Table 1).

Table 2 lists the statistically significant variables from the logistic regression model. Among the individual level factors, increasing maternal age and having two or more sons are associated with higher odds of sterilisation. Being Muslim, belonging to a scheduled caste/tribe, or having media exposure to family planning reduces the odds of using female sterilisation. Among the household level variables, a higher standard of living is associated with lesser odds of using sterilisation.

\section{Discussion}

According to the NFHS-2 data, sterilisation continues to be the main method of family planning across most of India.

Table 1 Descriptive characteristics of women using female sterilisation versus other methods of contraception in rural Bihar

\begin{tabular}{|c|c|c|}
\hline Variable & $\begin{array}{l}\text { Other methods }(\%) \\
(n=273)\end{array}$ & $\begin{array}{l}\text { Female sterilisation }(\%) \\
(n=1105)\end{array}$ \\
\hline \multicolumn{3}{|c|}{ Individual-level variables } \\
\hline \multicolumn{3}{|c|}{ Maternal age (years)*** } \\
\hline$<24$ & 20.1 & 4.8 \\
\hline $25-34$ & 42.9 & 40.4 \\
\hline$>35$ & 37 & 54.8 \\
\hline \multicolumn{3}{|l|}{ Living sons $(\mathrm{n}) * * *$} \\
\hline$\leq 1$ & 45.4 & 20.0 \\
\hline$\geq 2$ & 54.6 & 80.0 \\
\hline \multicolumn{3}{|l|}{ Living daughters (n) } \\
\hline$\leq 1$ & 57.1 & 53.2 \\
\hline$\geq 2$ & 42.9 & 46.8 \\
\hline \multicolumn{3}{|l|}{ Maternal education*** } \\
\hline Uneducated & 57.1 & 69.6 \\
\hline Has some education & 42.9 & 30.4 \\
\hline \multicolumn{3}{|l|}{ Husband's education* } \\
\hline Uneducated & 25 & 31.0 \\
\hline Has some education & 75 & 69.0 \\
\hline \multicolumn{3}{|l|}{ Religion*** } \\
\hline Hindu & 90 & 96.8 \\
\hline Muslim & 10 & 3.2 \\
\hline \multicolumn{3}{|l|}{$\begin{array}{l}\text { Scheduled caste/tribe/ } \\
\text { backward class* }\end{array}$} \\
\hline No & 20.2 & 25.4 \\
\hline Yes & 79.8 & 74.6 \\
\hline \multicolumn{3}{|l|}{$\begin{array}{l}\text { Heard about family } \\
\text { planning on radio, TV or } \\
\text { poster*** }\end{array}$} \\
\hline No & 39.9 & 52.2 \\
\hline Yes & 60.1 & 47.8 \\
\hline \multicolumn{3}{|c|}{ Household-level variables } \\
\hline \multicolumn{3}{|c|}{ Household size $(n)$} \\
\hline$\leq 6$ & 42.1 & 47.2 \\
\hline$>6$ & 57.9 & 52.8 \\
\hline \multicolumn{3}{|l|}{$\begin{array}{l}\text { Household standard of } \\
\text { living*** }\end{array}$} \\
\hline Low & 33.6 & 39.6 \\
\hline Medium & 43.5 & 47.0 \\
\hline High & 22.9 & 13.4 \\
\hline \multicolumn{3}{|l|}{$\begin{array}{l}\text { Permission required to } \\
\text { go out of the house }\end{array}$} \\
\hline No & 22.0 & 22.5 \\
\hline Yes & 78.0 & 77.5 \\
\hline \multicolumn{3}{|l|}{$\begin{array}{l}\text { Health care-seeking } \\
\text { decision maker*** }\end{array}$} \\
\hline Respondent & 13.6 & 18.8 \\
\hline Husband & 44.0 & 50.5 \\
\hline $\begin{array}{l}\text { Respondent/husband } \\
\text { jointly }\end{array}$ & 25.3 & 20.8 \\
\hline Others in family & 17.1 & 9.9 \\
\hline
\end{tabular}

${ }^{*} p<0.1, * * p<0.05, * * * p<0.001$.
Table 2 Logistic regression analysis of the odds of using female sterilisation versus other methods of contraception in rural Bihar $(\mathrm{n}=1364)$

\begin{tabular}{ll}
\hline Variable & Odds ratio \\
\hline Individual-level variables & \\
Maternal age (years) & \\
$\quad<24$ & - \\
$25-34$ & $3.94 * * *$ \\
$>35$ & \\
Living sons ( $n)$ & - \\
$\quad \leq 1$ & $2.77^{* * * *}$ \\
$\geq 2$ & \\
Religion & - \\
$\quad$ Hindu & $0.22^{* * *}$ \\
$\quad$ Muslim & \\
Scheduled caste/tribe/backward class & - \\
$\quad$ No & $0.49 * *$ \\
$\quad$ Yes & \\
Heard about family planning on radio, TV or poster & - \\
$\quad$ No & $0.73^{*}$ \\
Yes & \\
Household-level variables & \\
Household standard of living & - \\
$\quad$ Low & $\mathrm{NS}$ \\
Medium & $0.60^{*}$ \\
High &
\end{tabular}

Standard errors have been adjusted for clustering at the village level. ${ }^{*} p<0.1, * * p<0.05, * * * p<0.001$. NS, not significant.

For example, $96 \%$ of all users are sterilised in Andhra Pradesh; in Maharashtra, Madhya Pradesh, Bihar and Rajasthan the rate varies from $80 \%$ to $90 \% .^{2}$

Among the individual level determinants, the odds of a woman being sterilised increased with her age and with the number of living sons, while the number of living daughters did not have an impact. In the current study, the mean age of sterilised women in the sample was 35.6 years; the majority had been sterilised between the age of 25 and 29 years. This seems to validate the common perception that Indian women seek to complete their family after marriage. Once they have achieved the requisite number of living sons, they adopt sterilisation as a terminal method of birth control. 3,4

Muslim women were significantly less likely to be sterilised compared to Hindu women, and this may be a reflection of their religious beliefs regarding contraception and family size. ${ }^{5,6}$ Similarly, women from the deprived sections of society (scheduled castes/tribes) were much less likely to be sterilised. Saha ${ }^{6}$ noted an increase in the rate of sterilisation among scheduled caste/tribe women in his study, which he postulated was possibly due to the extreme poverty and the special monetary incentives provided to them. In the present study, the low odds of sterilisation for scheduled caste/tribe women could perhaps be indicative of a lack of access to reproductive health services for these women.

Education - both maternal and paternal - was not found to be a significant determinant, perhaps because its effects are being mediated through the effect of standard of living. While studies in India clearly demonstrate the association between education and contraceptive use,, 7 few reports document the impact (or lack thereof) of education on the choice between sterilisation and other contraceptive methods. Baveja et al. ${ }^{3}$ report an association between illiteracy and increased acceptance of sterilisation, but they did not control for other covariates in their analytic model. A study by Benjamin and Varagunasingh ${ }^{9}$ from North India also did not find education to be a significant influence on the adoption of sterilisation. It may be that education plays an important role in the decision to use or not use 
contraception, but once this decision is made, it does not impact on the choice among methods. In consonance with the literature, exposure to family planning messages via mass media was found to be a significant determinant of the choice between sterilisation and other contraceptive methods. ${ }^{7,10}$

Of the household level variables, the standard of living was the only significant determinant: households with a higher standard of living were less likely to use female sterilisation as a contraceptive method. ${ }^{4,11}$ This may reflect the lack of wherewithal for the poorer households to obtain other contraceptive methods, or it may reflect the impact of monetary incentives for sterilisation, which will have a bigger effect on poorer households.

From the policy perspective, this study underscores the need to significantly broaden the contraceptive choice for women in rural Bihar. It is estimated that only $18 \%$ of sterilised couples have ever used any other methods besides sterilisation. ${ }^{2}$ More attention should be given to educating the population about other contraceptive methods. Mass media such as radio and television are being used for information, educating and counselling campaigns, but consideration should also be given to local approaches such as local women's organisations. ${ }^{5}$ While son preference is entrenched in the Indian culture, ${ }^{12,13}$ steps should nonetheless be taken to improve the welfare and standing of the girl child and uplift the status of women in general. Innovative programmes such as those being implemented in the state of Haryana, which ensure a monetary reward to the family for the completion of schooling by female children, should also be implemented in Bihar.

While this study shows that Muslim and scheduled castes/tribes/backward class women are less likely to use sterilisation, more research is needed to understand their contraceptive use patterns to ensure that these groups do indeed have access to the health care system and that culturally appropriate messages can be developed to reach out to these communities. From the provider perspective, women should be given appropriate counselling and offered a choice of methods, so that they choose a contraceptive method that best suits their needs and desires. Baveja et al. ${ }^{3}$ clearly demonstrate that when women are given the freedom to choose, most women will override provider bias and make an informed choice. In their study, when women were given a balanced presentation of available contraceptive methods, $60 \%$ preferred the IUD. ${ }^{3}$

It is important to keep in mind certain caveats of the present study. The predictive model does not include variables to control for quality of care or motivation. The comparison group is heterogeneous and includes permanent (vasectomy) and non-permanent (e.g. pill, condom, etc.) methods, which may not have the same behavioural dimensions. Given the characteristics of rural Bihar, care should be exercised in extrapolating these results to other states of India.

The recently promulgated NPP is a step in the right direction. It has identified and brought into focus issues that the government is committed to addressing, such as using the village as the locus of efforts. One strategic theme in the NPP is to bring an integrated package of essential services, including reproductive services, to the village level and involving both governmental and nongovernmental organisations in this effort. In a similar vein, the stated goal of providing "a wider, affordable choice of contraceptives $\ldots$ at diverse delivery points, with counselling services to enable acceptors to exercise voluntary and informed consent ..." is laudable..$^{1}$ This analysis highlights the usefulness of the NFHS-2 data in conducting analyses at the state level and in stimulating further research to help improve the health of vulnerable population groups in India.

\section{Statements on funding and competing interests \\ Funding. None identified.}

Competing interests. None identified.

\section{Author Note}

An unfortunate characteristic of the Indian social milieu is stratification of the population based on caste. Many lower castes are treated as untouchables and they are among the most downtrodden members of Indian society. In Constitution includes a list of castes and tribes in its schedules for whon special benefits (such as reservations in educational institutions, employment, etc.) are enshrined. Persons belonging to these 'scheduled castes or tribes' are considered to be at the bottom of the social order and are some of the most underprivileged and disadvantaged individuals in Indian society.

References

1 Ministry of Health and Family Welfare. National Population Policy, 2000. New Delhi, India: Ministry of Health and Family Welfare, 2000

2 Roy TK, International Institute for Population Sciences, ORC Macro MEASURE/DHS+ (Programme). National Family Health Survey (NFHS-2), 1998-99: India. Mumbai, India; Calverton, MD: International Institute for Population Sciences; Measure DHS+ ORC Macro, 2000.

3 Baveja R, Buckshee K, Das K, Das SK, Hazra MN, Gopalan S, et al. Evaluating contraceptive choice through the method-mix approach. An Indian Council of Medical Research (ICMR) Task Force Study. Contraception 2000; 61: 113-119.

4 Agarwal N, Deka D, Takkar D. Contraceptive status and sexual behavior in women over 35 years of age in India. Adv Contracept 1999; 15: 235-244.

5 Chacko E. Women's use of contraception in rural India: a villagelevel study. Health Place 2001; 7: 197-208.

6 Saha SP. Trend of socio-demographic characteristics of tubectomy acceptors in a rural area of West Bengal (Singur). Indian J Public Health 1981; 25: 102-110

7 Dwivedi SN, Sundaram KR. Epidemiological models and related simulation results for understanding of contraceptive adoption in India. Int J Epidemiol 2000; 29: 300-307.

8 Stephenson R, Tsui AO. Contextual influences on reproductive health service use in Uttar Pradesh, India. Stud Fam Plann 2002; 33: 309-320.

9 Benjamin RE, Varagunasingh TV. Social and demographic characteristics influencing adoption of female sterilisation. Bull Gandhigram Inst Rural Health Fam Welf Trust 1982; 17-18: 21-33.

10 Retherford RD, Mishra V. Media exposure increases contraceptive use. Natl Fam Health Surv Bull 1997; 7: 1-4.

11 Mittal MC, Tiwari SC, Patodi RK. A study of some sociodemographic characteristics of human sterilization cases in the area demographic characteristics of human sterilization cases in the area Public Health 1977; 21: 65-70.

12 Clark S. Son preference and sex composition of children: evidence from India. Demography 2000; 37: 95-108.

13 Nielsen BB, Liljestrand J, Hedegaard M, Thilsted SH, Joseph A. Reproductive pattern, perinatal mortality, and sex preference in rural Tamil Nadu, south India: community based, cross sectional study. BMJ 1997; 314: 1521-1524.

\section{Visit the Faculty Website at: www.ffprhc.org.uk}

